\title{
Remission with Cabergoline in Adolescent Boys with Cushing's Disease
}

\author{
Ayla Güven1, Feyyaz Baltacıoğlu2, Fatma Dursun1, Ayşe Nurcan Cebeci1, Heves Kırmızıbekmez1 \\ 1 Göztepe Education and Research Hospital, Pediatric Endocrinology Clinic, Istanbul, Turkey \\ 2Marmara University, Medical Faculty, Department of Radiology, Istanbul, Turkey
}

\begin{abstract}
Cabergoline is a long-acting dopamine receptor agonist used for treatment of patients with uncured Cushing's disease (CD) and, as a first-line treatment, was used in only limited numbers of patients. This report presents two adolescent boys with $C D$ who were treated with cabergoline. Two adolescent boys with clinical and laboratory findings of $\mathrm{CD}$ are presented. No pituitary adenoma was detected by radiological investigation in either patient. Adrenocorticotropic hormone (ACTH) hypersecretion and lateralization was found by inferior petrosal sinus sampling in both patients. The initial cabergoline dose was $1 \mathrm{mg} /$ week and was adjusted up to $1.5 \mathrm{mg} /$ week in the second patient, based on his urinary free cortisol (UFC) level. The patients responded to cabergoline treatment with normal UFC levels on the $4^{\text {th }}$ and $6^{\text {th }}$ months of treatment. The boys reached complete remission at the end of the $17^{\text {th }}$ and $24^{\text {th }}$ months, respectively. Cabergoline is effective in the control of cortisol secretion and can be considered as a first-line treatment in cases of CD.

Key words: Cushing's disease, cabergoline, adolescent, inferior petrosal sinus sampling
\end{abstract}

Conflict of interest: None declared Received: 03.03.2013
Accepted: 25.04 .2013

\section{Introduction}

Cushing's disease (CD) caused by a corticotrophic pituitary tumor is the most common form of Cushing's syndrome $(1,2,3)$. Transsphenoidal surgery is the first-choice treatment for most patients with CD. Surgery is effective in inducing immediate disease remission in around $70 \%$ and late disease remission in around $50 \%$ of patients $(4,5,6)$. Pituitary irradiation and bilateral adrenalectomy are the alternative therapeutic approaches to $C D$, but these interventions can be associated with severe complications (7).

There is still a strong need for a medication option in the management of CD. Medication treatment usually consists of use of adrenal-blocking drugs and neuromodulatory drugs acting at the pituitary level $(8,9)$. However, inhibitors of steroidogenesis and the adrenolytic agent mitotane have limited efficacy or cause side effects that restrain their long-term utilization (5). Studies on using dopamine agonists like bromocriptine or cabergoline were started following the demonstration of $D_{2}$ receptor expression in corticotroph tumors (10). The effect of these drugs on adrenocorticotropic hormone (ACTH) and cortisol secretion was reported in a few in vitro and in vivo studies $(10,11)$. A higher affinity and specificity of cabergoline for $D_{2}$ receptors in addition to its longer half-life $(12,13)$ could explain its better efficacy in CD. Reports of successful outcome range from 25 to $75 \%$ in shortcourse treatment of persistent or recurrent CD $(14,15)$. However, data pertaining to cabergoline as a first-line therapy in cases of $\mathrm{CD}$ are scarce. Experience with cabergoline in childhood and adolescence is also limited (16). Here, we describe two boys with CD (17 and 15 years old), in whom first-line cabergoline treatment was effective in inducing remission.

Address for Correspondence

Ayla Güven MD, Göztepe Education and Research Hospital, Pediatric Endocrinology Clinic, Istanbul, Turkey

Phone: +902165664000 E-mail: aylaguven@yahoo.com

(C) Journal of Clinical Research in Pediatric Endocrinology, Published by Galenos Publishing. 


\section{Case Reports}

Patient 1: A 17-year-old male who presented with weight gain and hypertension was found to show the clinical features of CD including obesity, pink striae, and acanthosis nigricans. His weight was $92 \mathrm{~kg}$, height $175 \mathrm{~cm}$. Body mass index (BMI) was $30 \mathrm{~kg} / \mathrm{m}^{2}$, blood pressure 140/100 $\mathrm{mmHg}$, and pubertal stage was Tanner V. Clinical features and hormonal workup are shown in Table 1. Investigations revealed findings suggestive of $\mathrm{ACTH}$-dependent $\mathrm{CD}$, as follows: a basal cortisol level of $28 \mu \mathrm{g} / \mathrm{dL}$ (N: 6.7-22.6), a basal ACTH level of $168 \mathrm{pg} / \mathrm{mL}$ (N: 0-46), midnight cortisol of $17.5 \mu \mathrm{g} / \mathrm{dL}(\mathrm{N}<7.5)$ (17), midnight ACTH of $38.4 \mathrm{pg} / \mathrm{mL}$ (sample taken between 11:00 -12:00 p.m.), overnight dexamethasone suppression (ODS) cortisol of $1.18 \mu \mathrm{g} / \mathrm{dL}$, and 24-hour urine free cortisol (UFC) of $504 \mu \mathrm{g} /$ day ( $N$ <180). Repeated UFC values were $251 \mu \mathrm{g} /$ day and $302 \mu \mathrm{g} /$ day, respectively. A low-dose dexamethasone suppression test (LDDST) led to a cortisol level of $0.17 \mu \mathrm{g} / \mathrm{dL}$ and UFC of $11 \mu \mathrm{g} /$ day $(\mathrm{N}<10)$. Because the cortisol level was found to be suppressed and UFC was at a borderline level, we did not feel the need to perform any further investigations. However, in the follow-up period, the patient was observed to have uncontrolled hypertension, and we were not able to attribute this finding to any other cause. Echocardiograpic examination, renal Doppler ultrasound, and renal magnetic resonance imaging (MRI) angiography were performed and revealed normal findings. The patient's plasma renin, aldosterone, and catecholamine levels were also within normal ranges. Gadolinium-diethylenetriamine pentaacetic acid (Gd-DTPA)-enhanced MRI of the pituitary gland, abdomen and thorax was performed, and the results were normal. After stimulation with $100 \mu \mathrm{g}$ corticotropinreleasing hormone $(\mathrm{CRH})$, inferior petrosal sinus sampling (IPSS) showed a central to peripheral ratio of $4(\mathrm{~N}<3)$ and lateralization to the right side with a ratio of 3.98 (Table 2). The patient was diagnosed as CD, and treatment with $1 \mathrm{mg} /$ week cabergoline (given twice a week) was initiated. In the fourth month of treatment, the blood pressure returned to normal and UFC decreased to 112 and $130 \mu \mathrm{g} /$ day in two samples. On the $17^{\text {th }}$ month of treatment, the patient, receiving $1 \mathrm{mg} /$ week cabergoline, was still in remission. No adverse effect of cabergoline was observed during the follow-up period.

Patient 2: A 15-year-old male presented with weight gain and hypertension. He weighed $107 \mathrm{~kg}$ and was $172 \mathrm{~cm}$ tall (Table 1). His blood pressure was $160 / 100 \mathrm{mmHg}$, BMI $37 \mathrm{~kg} / \mathrm{m}^{2}$, and pubertal development was Tanner stage $\mathrm{V}$. $\mathrm{He}$ had a moon face and generalized obesity. Investigations were suggestive of ACTH-dependent CD: basal cortisol of $26 \mu \mathrm{g} / \mathrm{L}$, basal ACTH of $135 \mathrm{pg} / \mathrm{mL}$, ODS serum cortisol of $15.9 \mu \mathrm{g} / \mathrm{dL}$, 24-hour UFC of $481 \mu \mathrm{g} / \mathrm{day}$, midnight cortisol level of $14.5 \mu \mathrm{g} / \mathrm{dL}$, LDDST serum cortisol level of $0.48 \mu \mathrm{g} / \mathrm{L}$, and UFC of $13.1 \mu \mathrm{g}$ /day. Gd-DTPA-enhanced MRI of the pituitary gland, abdomen, and the thorax revealed normal results. Stimulated IPSS with $100 \mu \mathrm{g} \mathrm{CRH}$ showed a central to peripheral ratio of $5.7(\mathrm{~N}<3)$ and lateralization to the right side with a ratio of 2.8 (Table 2 ). The patient was diagnosed as $\mathrm{CD}$, and treatment with $1 \mathrm{mg} /$ week cabergoline (given twice a

\begin{tabular}{|c|c|c|c|c|}
\hline & \multicolumn{2}{|c|}{ Before treatment } & \multicolumn{2}{|c|}{ After treatment } \\
\hline & Patient 1 & Patient 2 & Patient 1 & Patient 2 \\
\hline Age (years) & 17 & 15 & & \\
\hline Gender & male & male & & \\
\hline Weight (kg) & 92 & 107 & 91 & 101 \\
\hline Height (cm) & 175 & 172 & 179 & 172 \\
\hline Body mass index $\left(\mathrm{kg} / \mathrm{m}^{2}\right)$ & 30 & 37 & 28 & 34 \\
\hline Arterial blood pressure (mmHg) & $140 / 100$ & $150 / 100$ & $125 / 70$ & $130 / 90$ \\
\hline Basal cortisol level ( $\mu \mathrm{g} / \mathrm{dL})$ & 28 & 26 & 19 & 25 \\
\hline Basal ACTH level (pg/mL) & 165 & 135 & 24.5 & 33 \\
\hline Cortisol level at midnight $(\mu \mathrm{g} / \mathrm{dL})(\mathrm{N}<7.5)$ & 17.5 & 14.5 & & \\
\hline ACTH level at midnight (pg/mL) & 38.4 & 34 & & \\
\hline 24-hour urine free cortisol ( $\mathrm{N}<180 \mu \mathrm{g} /$ day) & 504 & 481 & 112 and 130 & 132 and 72 \\
\hline Serum cortisol level after ODS $(\mathrm{N}<1.8 \mu \mathrm{g} / \mathrm{dL})$ & 1.18 & 15.9 & & 0.9 \\
\hline 24-hour urine free cortisol level after LDDS ( $\mathrm{N}<10 \mu \mathrm{g} /$ day) & 11 & 13.1 & & \\
\hline Serum cortisol level after LDDS ( $\mathrm{N}<1.8 \mu \mathrm{g} / \mathrm{dL})$ & 0.17 & & & \\
\hline
\end{tabular}


Table 2. Results of IPSS and radiological findings in the two patients

\begin{tabular}{|c|c|c|c|c|c|c|}
\hline \multirow[t]{2}{*}{ Minutes } & \multicolumn{2}{|c|}{ Peripheral vein ACTH (pg/mL) } & \multicolumn{2}{|c|}{ Left petrosal sinus ACTH (pg/mL) } & \multicolumn{2}{|c|}{$\begin{array}{l}\text { Right petrosal sinus ACTH } \\
(\mathrm{pg} / \mathrm{mL})\end{array}$} \\
\hline & Patient 1 & Patient 2 & Patient 1 & Patient 2 & Patient 1 & Patient 2 \\
\hline-3 & 37.2 & 245 & 81.4 & 1408 & 147 & 276 \\
\hline 0 & 38.2 & 260 & 36.8 & 1744 & 83.3 & 357 \\
\hline 3 & 58.2 & 230 & 57.4 & 2904 & 227 & 335 \\
\hline 5 & 59.1 & 349 & 65.5 & 2935 & 210 & 379 \\
\hline 10 & 43.9 & 500 & 60.0 & 1690 & 148 & 1330 \\
\hline Central/peripheral ratio $(\mathrm{N}<3)$ & & & \multicolumn{2}{|c|}{4} & \multicolumn{2}{|c|}{5.7} \\
\hline IPSS lateralization ( $\mathrm{N}<2$ ) & & & \multicolumn{2}{|c|}{ Right: 3.98} & \multicolumn{2}{|c|}{ Left: 2.8} \\
\hline Cabergoline dose/week & & & \multicolumn{2}{|c|}{ 1mg (twice a week) } & \multicolumn{2}{|c|}{$1.5 \mathrm{mg}$ (twice a week) } \\
\hline Result & & & \multicolumn{2}{|c|}{ Remission after 4 months } & \multicolumn{2}{|c|}{ Remission after 6 months } \\
\hline Duration of treatment & & & \multicolumn{2}{|c|}{17 months } & \multicolumn{2}{|c|}{24 months } \\
\hline MRI of pituitary & & & \multicolumn{2}{|c|}{ Normal } & \multicolumn{2}{|c|}{ Normal } \\
\hline Thorax and abdominal MRI & & & \multicolumn{2}{|c|}{ Normal } & \multicolumn{2}{|c|}{ Normal } \\
\hline
\end{tabular}

week) was started. At the second month of therapy, the 24hour UFC was still $210 \mu \mathrm{g} /$ day, and the cabergoline dose was increased to $1.5 \mathrm{mg} /$ week. On the sixth month of treatment, cortisol level in ODS test was $0.9 \mu \mathrm{g} / \mathrm{dL}$, and UFC was 132 and $72 \mu \mathrm{g} /$ day in two samples. Blood pressure at this time had decreased to $130 / 90 \mathrm{mmHg}$. During the follow-up period, UFC was measured successively at intervals of 1-2 months. The patient was in remission by the $24^{\text {th }}$ month of cabergoline treatment, administered as $1.5 \mathrm{mg}$ twice weekly. No adverse effect was observed during cabergoline treatment.

\section{Discussion}

$C D$ in childhood is a rare disorder that is generally caused by pituitary or ectopic ACTH-secreting tumors. Surgery is the principal therapeutic modality. No ACTH-secreting tumor was demonstrated by radiologic imaging methods in either of our two patients. Both patients underwent dynamic Gd-DTPAenhanced MRI investigation using coronal sequences, and no hypothalamic or pituitary lesion was detected. However, it is known that MRI investigation can detect tumors in only about $50 \%$ of all cases. Pituitary tumors cannot be distinguished from the pituitary gland tissue, especially if they are small or have the same imaging character as the gland. In such cases, spoiled gradient sequences, which have thinner slice thicknesses and provide better tissue discrimination, should be obtained. We did not have the means to use this technique in the imaging studies of our patients. However, determination of an ACTH gradient by IPSS, on the right side in one patient (Patient 1) and on the left side in the other patient (Patient 2) suggested the presence of microadenoma which could not be detected in MRI.
Cyclic Cushing's syndrome is a pattern of hypercortisolism in which cortisol production fluctuates. This syndrome is often associated with fluctuating symptoms and signs. Large cyclical fluctuations about every 10 days over 40 days, confirmed by repeated measurements, have been reported (18). Between exacerbations, urine and serum cortisol levels were found to be within normal ranges. Cyclic CD is very rare in childhood (19). Cyclic CD could be associated with primary pigmented nodular adrenocortical disease (20).

Serum and urine cortisol levels of our first patient were abnormal initially. The urine free cortisol was high in repeated samples. This patient had intractable hypertension and weight gain. However, because cortisol was found to be suppressed by dexamethasone and UFC was at the borderline level, we did not feel the need to perform any further investigations and did not suspect cyclic CD initially in this patient. The IPSS performed during the follow-up period helped us establish the diagnosis.

The expression and function of the $D_{2}$ receptors in corticotroph pituitary tumors has been demonstrated in earlier studies. The presence of functional $\mathrm{D}_{2}$ receptors in $60 \%$ and the demonstration of effectiveness of a short-term treatment with the dopamine agonist cabergoline in normalizing ACTH and cortisol secretion in $40 \%$ of corticotroph pituitary tumors strongly support the possible therapeutic use of this drug in the management of persistent and/or recurrent CD (7). Cabergoline was described as having potential positive metabolic effects. It could lower blood pressure and improve glucose tolerance independent of its cortisol-lowering effect. Dopamine agonists lower peripheral resistance relaxing vascular wall smooth muscles, with consequent improvement of blood pressure (5). 
Cabergoline is usually used as a second-line therapy in patients with unsuccessful surgical removal of a secreting tumor $(5,7,16,21)$. Pivonello et al $(7)$ reported 20 patients with CD who were unsuccessfully treated by surgery. In this group, shortterm (3 months) and long-term (12-24 months) effectiveness of cabergoline was evaluated. While $75 \%$ of these patients responded to cabergoline treatment in short-term, in 8 of these $20(40 \%)$ patients, cabergoline treatment was found effective without significant side effects during a treatment period of 24 months. Vilar et al (21) also found a $25 \%$ complete response to cabergoline monotherapy in $12 \mathrm{CD}$ patients who had undergone transsphenoidal surgery with unsuccessful results and who received a maximal dose of $3 \mathrm{mg} /$ week of cabergoline for a period of 6 months.

Godbout et al (5) showed that short-term treatment with cabergoline in patients with $C D$ improves cortisol secretion in $50 \%$ of subjects, with complete normalization of UFC in $36.6 \%$ of cases. Long-term follow-up during a mean period of 37 months demonstrated sustained effectiveness of cabergoline in $30 \%$ of subjects with mostly persistent or recurrent $C D$. Cabergoline was used as a first-line therapy in three patients of their cohort (5). One of these patients demonstrated a complete normalization of UFC after 1 month of treatment with $1 \mathrm{mg} /$ week of cabergoline with regression of clinical signs following 18 months of treatment. The two other patients on first-line therapy did not respond after 3 months of treatment with 1.5 or $2 \mathrm{mg} /$ week of cabergoline (5).

Both our patients were treated with the dopamine agonist cabergoline and both showed a complete normalization of UFC after 6 months of treatment with doses of 1 and 1.5 mg/week, respectively. Both patients are still in remission with improved clinical symptoms and normal UFC at the end of $17^{\text {th }}$ and $24^{\text {th }}$ months, respectively.

In adults, cabergoline was also used in CD caused by macroadenomas. Beside the control of aberrant ACTH secretion, significant reduction and stabilization of macroadenoma volume was demonstrated by cabergoline treatment in patients with $C D$ $(14,22)$.

Although data about cabergoline as first-line therapy in $C D$ are very limited, the safety profile of this product, its relative efficacy, and its surgery-sparing potential appear to warrant the need for prospective studies on its long-term efficacy in larger cohorts of patients with $C D$. An extensive literature search revealed only a few reports of adolescent patients who were treated with cabergoline because of persistent $C D$ after surgery and radiotherapy $(9,16)$. Cabergoline treatment in childhood was reported by Gopal et al (9). Their patient was a 12-year-old boy who had persistent $C D$ and who had undergone surgery and radiotherapy. The authors suggested that cabergoline was a useful option for inducing remission in uncured CD patients. Lila et al (16) reported 18 uncured CD patients, 4 of whom were adolescents treated with cabergoline. They found that cabergoline was an effective therapy in terms of LDDST and/or midnight cortisol results in $28 \%$ of patients with uncured CD. Our patients had a quite good response to treatment with no adverse effects.

In conclusion, cabergoline appears to be a particularly interesting first-line therapeutic option for patients with radiologically nondetectable $\mathrm{CD}$. Further studies on a larger population of patients are necessary to establish the definitive results of cabergoline treatment.

\section{References}

1. Pivonello R, De Martino MC, De Leo M, Lombardi G, Colao A. Cushing's Syndrome. Endocrinol Metab Clin North Am 2008;37:135-149.

2. Newell-Price J, Bertagna $X$, Grossman AB, Nieman LK. Cushing's syndrome. Lancet 2006;367:1605-1617.

3. Pivonello R, Faggiano A, Lombardi G, Colao A. The metabolic syndrome and cardiovascular risk in Cushing's syndrome. Endocrinol Metab Clin North Am 2005;34:327-339.

4. Biller BM, Grossman AB, Stewart PM, Melmed S, Bertagna $X$, Bertherat J, Buchfelder M, Colao A, Hermus AR, Hofland LJ, Klibanski A, Lacroix A, Lindsay JR, Newell-Price J, Nieman LK, Petersenn S, Sonino N, Stalla GK, Swearingen B, Vance ML, Wass JA, Boscaro M. Treatment of adrenocorticotropindependent Cushing's syndrome: a consensus statement. J Clin Endocrinol Metab 2008;93:2454-2462. Epub 2008 Apr 15

5. Godbout A, Manavela M, Danilowicz K, Beauregard H, Bruno OD, Lacroix A. Cabergoline monotherapy in the long-term treatment of Cushing's disease. Eur J Endocrinol 2010;163:709716. Epub 2010 Aug 11

6. Miller JW, Crapo L. The medical treatment of Cushing's syndrome. Endocr Rev 1993;14:443- 458.

7. Pivonello R, De Martino MC, Cappabianca P, De Leo M, Faggiano A, Lombardi G, Hofland LJ, Lamberts SW, Colao A. The medical treatment of Cushing's disease: effectiveness of chronic treatment with the dopamine agonist cabergoline in patients unsuccessfully treated by surgery. J Clin Endocrinol Metab 2009;94:223-230. Epub 2008 Oct 28

8. Nieman LK. Medical therapy of Cushing's disease. Pituitary 2002;5:77-82.

9. Gopal R, Bandgar T, Menon P, Shah N. Remission in Cushing disease with cabergoline. Ann Saudi Med 2008;28:224-225.

10. Pivonello R, Ferone $D$, de Herder WW, Kros JM, De Caro ML, Arvigo M, Annunziato L, Lombardi G, Colao A, Hofland LJ, Lamberts SW. Dopamine receptor expression and function in corticotroph pituitary tumors. J Clin Endocrinol Metab 2004;89:2452-2462.

11. de Bruin C, Hanson JM, Meij BP, Kooistra HS, Waaijers AM, Uitterlinden P, Lamberts SW, Hofland LJ. Expression and functional analysis of dopamine receptor subtype 2 and somatostatin receptor subtypes in canine cushing's disease. Endocrinology 2008; 149:4357-4366. Epub 2008 May 15

12. Colao A, di Sarno A, Pivonello R, di Somma C, Lombardi G. Dopamine receptor agonists for treating prolactinomas. Expert Opin Investig Drugs 2002;11:787-800.

13. Colao A, Lombardi G, Annunziato L. Cabergoline. Expert Opin Pharmacother 2000;1:555-574.

14. Miyoshi T, Otsuka F, Takeda M, Inagaki K, Suzuki J, Ogura T, Date I, Hashimoto K, Makino H. Effect of cabergoline treatment on Cushing's disease caused by aberrant adrenocorticotropinsecreting macroadenoma: J Endocrinol Invest 2004;27:10551059. 
Güven $A$ et al.

Cabergoline and Cushing's Disease

15. Godbout A, Beauregard H, Lacroix A. Cabergoline in the longterm treatment of Cushing's disease. The Endocrine Society's 89th Meeting, Toronto, Ontario, 2007: 4-51.

16. Lila AR, Gopal RA, Acharya SV, George J, Sarathi V, Bandgar T, Menon PS, Shah NS. Efficacy of cabergoline in uncured (persistent or recurrent) Cushing disease after pituitary surgical treatment with or without radiotherapy. Endocr Pract 2010;16:968-976.

17. Papanicolaou DA, Yanovski JA, Cutler GB Jr, Chrousos GP, Nieman LK. A single midnight serum cortisol measurement distinguishes Cushing's syndrome from pseudo-Cushing states. J Clin Endocrinol Metabol 1998;83:1163-1167.

18. Mullan KR, Atkinson AB, Sheridan B. Cyclical Cushing's syndrome: an update. Curr Opin Endocrinol Diabetes Obes 2007; 14:317-322.

19. Robyn JA, Koch CA, Montalto J, Yong A, Warne GL, Batch JA. Cushing's syndrome in childhood and adolescence. J Paediatr Child Health 1997:33:522-527.
20. Gunther DF, Bourdeau I, Matyakhina L, Cassarino D, Kleiner DE, Griffin K, Courkoutsakis N, Abu-Asab M, Tsokos M, Keil M, Carney JA, Stratakis CA. Cyclical Cushing syndrome presenting in infancy: an early form of primary pigmented nodular adrenocortical disease, or a new entity? J Clin Endocrinol Metab 2004;89:3173-3182

21. Vilar L, Naves LA, Azevedo MF, Arruda MJ, Arahata CM, Moura E Silva L, Agra R, Pontes L, Montenegro L, Albuquerque JL, Canadas V. Effectiveness of cabergoline in monotherapy and combined with ketoconazole in the management of Cushing's disease. Pituitary 2010;13:123-129.

22. Manavela MP, Danilowicz K, Bruno OD. Macrocorticotropinoma shrinkage and control of hypercortisolism under long-term cabergoline therapy: case report. Pituitary 2012;15(Suppl 1):33-36. 